\title{
28 Research Square \\ Understanding International Agenda using Media Analytics: The case of Disaster News Coverage in Indonesia
}

Adiwan Aritenang ( $\square$ a.aritenang@gmail.com )

Institut Teknologi Bandung (ITB)

Research

Keywords: Media Analytics, GDELT, Disaster News, Earthquake, Indonesia

Posted Date: March 11th, 2021

DOI: https://doi.org/10.21203/rs.3.rs-286133/v1

License: (c) (1) This work is licensed under a Creative Commons Attribution 4.0 International License.

Read Full License 


\section{Abstract}

Recently, the flow of data has increased rapidly in terms of volume, velocity, variety, veracity, and value (5Vs). One of the potential sources of data is the worldwide news provided by the Global Data on Event Location and Tone (GDELT) project that reports events. The large database on global events allow the platform as a source for big data analysis that potentially signify our understanding on the extent of event reports. This paper questions the inter-news coverage between foreign and domestic media on the earthquake and tsunami in Palu and Donggala. The paper conducts two main analysis; first, exploratory of news reported from selected countries with highest size of aid (USA, Australia, Europe and Japan) and vice versa, Indonesia news on the respective countries aid activities. Second, media linkages are captured using visualization with statistical graph and spatial flow of news. The paper found that the dynamic of news broadcast on disaster are varied between countries and its coverage fluctuated in all countries. The paper contributes to presence of newsworthiness on disaster news coverage, and consequently lack of coverage on disaster meaning and mitigation plans.

\section{Introduction}

International news importance has become increasing since the globalization and intensive communication of people worldwide. The need to understand current event in other parts of the world has rapidly grew as global business and international affairs intensifies. In the international communication and journalism notion, news transmitted from other countries tend to influence audience's perception and attitude towards these countries $(\mathrm{Wu}, 1998)$. This became more pronounce when this foreign news, with its agenda-setting programs, is the only source of information and thus, shapes the public opinion on the particular country.

In the news flow and coverage on natural disaster, the period is shorter than other issues as the coverage tended to be rapidly updated, focus on the current impact of disasters on humans, the built environment, and economics (Houston, Pfefferbaum and Rosenholtz, 2012). The media also plays a role to inform and determine priorities recovery, also to shape public's perception on natural risks and influence individual strategies over mitigation of future vulnerabilities Miles and Morse (2006). However, presently there is lack of study that examines the inter-news coverage between international and domestic media on disaster. This is important to understand the respective countries' interest and the reasons, so the countries could examine current international relationship and agenda.

As such, this paper questions the inter-news coverage between foreign and domestic media on the earthquake and tsunami in Palu and Donggala. We investigate how dynamic is the news broadcast in selected foreign countries on disasters in Indonesia and to what extent the dynamic of local news in Indonesia covers the respective selected foreign country on the issue.

Using the GDELT database, the research aims to provide preliminary international news coverage analysis with contemporary data and analytical tools. Furthermore, the paper filters news data on the disaster 
from the highest aid provide countries and Indonesia and from Indonesia on the news of the respective foreign countries aid programs. The geocode available on each news also allows to visualize the news flow on the location of the news and the location of area where the news are reporting.

The remainder of the paper is structured as followed; the following section describes the literature review of disaster news coverage and the use of GDELT database on similar topic. In section three and four, the data and methodology, and analysis of the dynamics and spatial flow of news coverage are discussed, respectively. The last section concluded the research on the potential of big data to obtain new information and insights on news media coverage between countries.

\section{li. Literature Context}

In this article, we frame the research framework using the newsworthiness theory and the news media on natural disasters analysis. The newsworthiness theory developed by Galtung and Ruge (1965) suggests news are worth reported based on psychology of individual perception such as importance in one factor could be offset by another factor. In further detail, Kwak and An (2014) argues these factors are frequency, intensity, unambiguity, meaningfulness, consonance, unexpectedness, and the continuity of an event. This leads to the decision for media companies to report which news items through their channels such as newspapers and TV news.

However, in a more complex analysis, Wu (1998) argues that newsworthiness alone is not adequate to understand the determinants of international news flow. The two important factors on how international news are channelled are; first is the gatekeepers' perspective that include newsworthiness, socio-cultural structure, organizational constrains and the agenda-setting that international news services have. The attention and interest of international news regarding a foreign country may be steer by the news media agenda and the deviance of the event. Second, logistical factors argue that the clout of a country determines the news media interests of coverage including trade relationship, cultural background, and geographical proximity and regionalism.

While news flow and coverage in natural disaster are expected not only communicating the event and its physical and socio-economic impact, but also warning and contributing to individual and community preparedness, recovery, and resilience (Houston, Pfefferbaum and Rosenholtz, 2012). The paper further suggests that on average, news covers are shorter periods of time than other issues, coverage tended to focus on the current impact of disasters on humans, the built environment, and economics was an important topic. On the other hand, the study highlighted that there is little coverage of what caused the disaster, or what influenced responses to the disaster and what the disaster means for the people and communities experiencing the disaster. Thus, this may weaken the disaster narrative that hinders people to learn through from the news coverage any preparedness for themselves and understanding national or societal implications of those who experience the disaster.

There are several issues arose between media and disaster reports. First, demand for high speed and accurate information update. The study by Binderkrantz (2020) shows that traditional news such as 
newspaper, has been regarded slow for update public on disaster news as once it was disseminated, the information would already outdate. Furthermore, as media is strongly tied with interest groups, their framed messages would consequently highlight some features of reality and downplay others. In this sense, news frame could be seen as a weapon to generate support for specific action or policy. Second, the news coverage of natural disasters could define and limits the discourses related with these events. As natural disasters caused destruction and inhibits daily services, media coverage allows news of need for recovery of capital, social and build environment. For instance, the paper by Miles and Morse (2006) argues the these how media coverage that priorities recovery of various forms of capital - natural, human, social, and built shape the public' perception natural risks and how this influence individual strategies over mitigation of future vulnerabilities.

Presently the emerging on technology 4.0 has allow information technology to be distributed and accessible worldwide. Following the technology advancement, news coverage and its analytical methods has extended in the past decade. The abundance of data availability and new analytical methods allows one to analyse data in a much efficient and new way. This may be represented by datafication, referring to the use of digital technologies to release the knowledge associated with physical objects by decoupling them from the data associated with them. Explaining further, Mayer-Schonberger and Cukier (2013) argues that datafication shows that the indirect uses of texts and location data have nothing to do with the data itself, the purpose for which the information was initially generated. New uses emerge and new value can be created. For instance, as news texts become online copy, it is known as "digitized", while as these texts are indexed and searchable, this became datafication. Similarly, this shift is found in transportation sector as when defining shortest route and tracking became digitized, the revenues from loyalty programs, restaurant recommendations, and advertisement became datafication.

This shift is also found in the journalism sector as the information on broadcast, print and web news that are available offline and online, are accessible to be gathered and analyse. One of the sources of big data is the GDELT database, a platform that hosts millions of news worldwide since the 1980s. The comparison of GDELT with other similar sources show that GDELT is a powerful database. For instance, the paper by Kwak and An (2016) analyze that news obtained from GDELT and Event Registry (ER) are similar, despite both datasets are quite different in terms of scale and news sources. The GDELT collects 2.26 times to 6.43 times more documents than ER per day. The GDELT database also publishes documents in more varied languages per day on average, 64.1 and 14 languages, respectively.

There are many studies on various disciplines has deploy GDELT data. The study by Aritenang et al (2018) shows that news on a particular country in a country is important to shape the perspective and appropriate policy towards the former country's foreign perspectives. Furthermore, the study by Kwak and An (2014) suggests that the unexpectedness of an event that continuous for days are reinforced its newsworthiness over time. While Kwak and An (2016) shows that the database is dominated by English language news (more than 2 million articles) followed by Spanish (646.000) and Arabic (320.000). The paper further shows that that the Dailymail (UK) and Reuters (USA) are the largest source of article. 
In the disaster study, (Arva et al 2013), suggest that one has to carefully analyze the GDELT database. The study by Kwak and An (2014) highlights that as the US media are the most tracked and available from the GDELT database, the number of news on a certain disaster might be influenced by US news media. One way to avoid this bias is to use other global news that reports the disaster. Another study is to predict the value of news within the next few hours. The study by Nourbakhsh et al (2014) argues computation journalism using GDELT data has improves how journalism operates. The study uses NLP and machine learning techniques that allows the model to learn and predict disaster news that would have high values, obtained from a feed of local authorities and news media. For instance, the paper compares the disaster feed and Reuter News, and found that out of 18 disasters between the period of analysis, there were 8 events where the disaster feed was ahead of the news office.

\section{lii. Data And Methodology}

The data is obtained from the GDLET database available online. The database is also known as Conflict and Mediation Event Observations. Event and Actor (CAMEO) database that is updated every 15 minutes and provides a rich source for news on events, conflicts and social events worldwide gathered from wide range of international sources. Presently, the data base tracks news media in over 1000 languages globally. The large-scale database covers over 100 languages news with mostly on physical activities such as protest, strike, disaster and others, with more than 200,000 events data on Indonesia for the last 20 years (Aritenang, et al 2018).

This research limits the period of analysis for three weeks since the occurrence of the earthquake on September 28th 2018 to October 30th 2018. This period is chosen following preliminary analysis that the number of news on the disaster drop significantly after four weeks. Furthermore, we select news media from Australia, Europe, Japan and Europe as these countries provide the highest aid funding for the disaster recovery project for data availability from the GDELT database. We also include European Union as a news actor as the union could be considered as a single political identity that may provide aid and donation for such disaster. Furthermore, it should be noted that the limited number of news in this research are due to the small coverage of Indonesian news media and the relatively unknown area of Palu and Donggala globally.

\section{Methodology}

In this section we discuss methods deployed to conduct the analysis. First, we examine the dynamic of news occurrence in respective countries and region during the period. It should be noted that the research only considered English-news published in the selected countries. As a result, the number of news will not be as many as it would be in Indonesian native language.

Second, we also identify news in Indonesia that mentions the above countries aid policies for the disaster, both news in Jakarta and in Palu and Donggala. The occurrence of news in Jakarta may indicate that the central government has acknowledge the importance of the aid given by the respective countries. To 
conduct these queries, the news between Indonesia and the above countries are filtered using specific event codes which are presented in the following table (Table 1) using the Google cloud BigQuery tool.

\section{Table 1}

\section{GDELT - CAMEO Event Codes, Description and News Frequencies}

\begin{tabular}{|llll|}
\hline No & $\begin{array}{l}\text { CAMEO Event } \\
\text { Codes }\end{array}$ & CAMEO Event Description & $\begin{array}{l}\text { News } \\
\text { Frequencies }\end{array}$ \\
\hline 1 & 010 & Make statement, not specified below & 113 \\
\hline 2 & 023 & Appeal for aid, not specified below & 23 \\
\hline 3 & 033 & $\begin{array}{l}\text { Express intent to provide material aid, not specified } \\
\text { below }\end{array}$ & 45 \\
\hline 4 & 042 & Make a visit & 107 \\
\hline 5 & 060 & Engage in material cooperation, not specified below & 58 \\
\hline 6 & 070 & Provide aid, not specified below & 104 \\
\hline 7 & 071 & Provide economic aid & 32 \\
\hline 8 & 084 & Return, release, not specified below & 9 \\
\hline 9 & 086 & Allow international involvement not specified below & none \\
\hline
\end{tabular}

Our next query is to select all news between September 29th 2018 and October 30th 2018 as we assume that within one-month news topic would have change from disaster event to funding aid and humanitarian activities. Our BigQuery syntax example is presented in the following graph (Fig. 1). The Actor 1 countrycode refers to the country where the news is published and the Actor2countrycode refers to the country reported in the news published by Actor 1 . As the result also include other events that occurs at the same time, the results are then clean manually specifically for the Palu and Donggola earthquake disaster news. The cleaned query obtained 492 news url's including disaster event, emergency response, humanitarian operations and aid plans.

Third, we map both geographically these news coverages in the respective countries and news coverage in Indonesia about the respective countries to visualize and analyse the flow of news.

\section{Iv. Analysis}

This section displays the analysis of news coverage dynamics and visualize the spatial flow. First the intensity and length of period of the news varies between countries (Tables 2 and 3). With more than 340 news articles, on average, the likely impact (Goldstein scale index) and news tone on the disaster are low, 
3.1 and negative -2.42 , suggesting cooperative - non conflict events and sadness, respectively. The positive value of Goldstein index may interpret as the positive impact of the news event, for instance the President's visit to the disaster location.

\section{Table 2 Average Tone}

\begin{tabular}{|lccccl|}
\hline & Mean & Median & Max & Min & N \\
\hline United States & -2.82 & -3.65 & 5.10 & -8.93 & 207 \\
\hline Japan & -0.50 & -0.53 & 5.63 & -5.98 & 37 \\
\hline Australia & -1.94 & -1.52 & 6.71 & -6.17 & 75 \\
\hline Europe & -2.54 & -3.98 & 2.48 & -5.83 & 23 \\
\hline Overall & -2.35 & -3.01 & 6.71 & -8.93 & 342 \\
\hline
\end{tabular}

\section{Table 3 Goldstein Scale Index}

\begin{tabular}{|llllll|}
\hline & Mean & Median & Max & Min & N \\
\hline United States & 3.91 & 3.4 & 8 & -10 & 207 \\
\hline Japan & 3.57 & 2.8 & 8 & -4 & 37 \\
\hline Australia & 1.77 & 1 & 7.4 & -4.4 & 75 \\
\hline Europe & 3.50 & 3.4 & 7 & -4 & 23 \\
\hline Overall & 3.37 & 3 & 8 & -10 & 342 \\
\hline
\end{tabular}

The table below shows that the low Goldstein scale index ranges between -4 and -4.4 and average tone level -5.83 to -8.93 . The lowest in the US, with value of Goldsten scale (-10) and average tone (-4.7) the title "watch terrifying first hand vision shows destructive power Indonesian tsunami sweeps through streets" published in the New Zealand (www.tvnz.co.nz) and re-broadcasted by Reuters in the US.

\section{Dynamics of news coverage on Palu disaster in the selected countries}

The figure below shows the number of Palu and Donggala disaster news in four foreign countries; Australia, Europe, Japan and USA (Fig. 2). Overall, the earthquake news only lasts for 2 weeks after the event. The graph reveals that the disaster news was broadcasted in the occurrence day by news media in the USA and Japan. Whilst news media in Australia and Japan broadcasted the disaster after 2 days later. However, the disaster news had little attention in Europe and Japan, with only 5-7 news per day when it peaked during the first two weeks since the disaster. However, we also acknowledge the limited 
number of news in Japan on this disaster is due to news broadcasted in Japanese media tend to be in Japanese. On the other hand, in the USA, the disaster news persistently broadcasted more than 10 news per day for more than two weeks before it slumps for a week and peaked again in during the third week. In Australia, the news peaked only during the second week with news topics such as the earthquake, number of victims, discussions on Australia's donation plan (humanitarian assistance and also disaster recovery assistance).

\section{Dynamics of news coverage on selected countries related with aid in Palu}

The following figure depicts the number of four foreign countries activities related with Palu and Donggala disaster as reported by Indonesian-based news (Fig. 3). The graph uses 340 data of news coverage during the period of study. The graph shows that the news on aid and humanitarian assistance were only found for USA and Australia during the early days. The news for the respective countries related with the disaster peaked at the end of the first week with 5-29 news per day. The news coverage further declined and fluctuated for the following two weeks, especially in the USA and Australia. The news coverage faded three weeks after the disaster.

\section{Spatial Visualization of news coverage}

This sub-section visualizes the news coverage of Palu disaster in the Palu and Donggala on from both local and international news. Both map below was constructed from the news flow from each geocodedlocation. The news location is further filtered to only unique location, thus if there is any news from one location, we only select one of the news of its geolocation to visualize news flow.

The first map was constructed using 254 news flow that shows the news on the Palu and Donggala from domestic news (Fig. 4). This figure shows that the disaster news report is found from various locations in Indonesia, especially from Java and Sulawesi islands. The news coverage generally reported the activities related with the disaster event and management shown between the districts with the close link of the graph. Despite Balikpapan and Makassar as the two key logistic-hub, there is no news coverage on disaster-related about these two cities. One possible explanation is the limited news data available regarding this information.

The second map has 238 news flows that describes the news from abroad regarding the disaster in Palu and Donggala (Fig. 5). The figure shows that news coverage on the disaster reported numerous cities within selected countries. This could be explained that news coverage on the disaster including activities and humanitarian of these selected countries are reported in various cities. For instance, news in the USA comes from Georgia, Washington DC, New York, and Ohio. Whilst from Australia news coverage are from Western Australia, Queensland and Canberra.

\section{Conclusion}


In this paper we have showed the use of news article collected through the GDELT news database. The study reveals that big data analysis provides new information and insights on how news media in a particular country broadcasts certain news topic on another country. Using the earthquake disaster in Palu and Donggala from late September to October 2018, the paper analysed the dynamic and spatial flow of news coverage in the highest aid funder, namely Australia, Europe, Japan and USA.

The paper found the following conclusions; first, the dynamic of news broadcast on disaster are varied between countries. For instance, the earliest news coverage on the topic started early on the same day in USA and Japan, and it was only broadcasted in Australia and Europe about two days later. Furthermore, the research also shows specific cities where the news coverage originated from such as Georgia, Washington DC, New York, and Ohio in the USA and from Western Australia, Queensland and Canberra in Australia. This finding reveals that local news in foreign countries also reported disaster news that occurred in Palu and Donggola. Second, the coverage reported by Indonesian-based news during the early days were only found for USA and Australia, which peaked in the first week with 5-29 news per day. Whilst there were less than 7 daily news coverage on Japan and Europe suggested the low media attention on both actor activities related with the disaster, despite the relatively significant aid to Indonesia.

Finally, the paper contributed to the literature in two debate, first, in the newsworthiness theory, the paper shows that foreign country's international relationship and their news media agenda determine attention and interest of international news regarding a foreign another country. For instance, the news coverage never exceeded 7 news per day in both Japan and Europe, suggesting the less attention that the disaster acquired in both regions. Whilst the news peaked for several weeks with at least 14 news per day in the USA. Furthermore, newsworthiness also occurred due to geographical proximity and regionalism as found in the case of Australia as the news coverage fluctuated during the first three weeks before it peaks several times in the following weeks. This phenomenon could be explained that these new peaks occurred as it reports the aids that the Australian government provide during the respective weeks.

Second, in the role of news coverage on disasters, as we found the lack of news coverage on what the disaster means for the people and communities experiencing the disaster and plans for humanitarian assistance from the selected countries. This might confirm the findings and concern raised by Houston, Pfefferbaum and Rosenholtz (2012) in the paper on Major U.S. Natural Disasters that present news coverage plays limited role for the society to understand individual and community preparedness, recovery, and resilience. Although we realized that this may due to the limited time period of analysis, the finding highlighted the growing consensus for future research to examine the normative function of media in the context of disasters and how society could benefit from such function.

\section{Declarations}

\section{ACKNOWLEDGEMENT}


The author would like to thank Mr. Ganesha Mangkoesoebroto for providing on the visualization of the spatial news flow maps. The author also thanks Dr. Mizan Bisri for his comments and depth knowledge on disaster studies and GDELT data.

- Ethics approval

Not applicable

- Consent to participate

Not applicable

- Availability of data and material

Data will be share upon request

- Competing interests

No financial competing interests

- Funding

No financial support

- Authors' contributions

All conducted by the author

- Acknowledgements

No acknowledgement

\section{References}

1. Arva B, Beieler J, Fisher B, Lara G, Schrodt PA, Song W, Sowell M, Stehle S Improving forecasts of international events of interest. In the 3rd Annual Meeting of the European Political Science Association, Barcelona, Spain in June, 2013.

2. Aritenang AF, Herwanto GB, Suhermi N, Amin I, Frederika M. 2018. Shaping Regional Development Policy Through News Coverage: Potential and Limitation. PulseLab Jakarta.

3. Bennett R, Daniel M. "Media reporting of Third World disasters: the journalist's perspective". Disaster Prevention Management. 2002;11 No(1):33-42.

4. Binderkrantz AS. Interest group representation and framing in the media: A policy area perspective. $J$ Public Affairs. 2020. https://doi.org/10.1002/pa.2009. 
5. Galtung J, Ruge MH. The structure of foreign news the presentation of the congo, cuba and cyprus crises in four norwegian newspapers. Journal of Peace Research. 1965;2(1):64-90.

6. Houston JB, Pfefferbaum B, Rosenholtz CE. Disaster News: Framing and Frame Changing in Coverage of Major U.S. Natural Disasters, 2000-2010. Journalism Mass Communication Quarterly. 2012;89(4):606-23.

7. Kwak H, An J. 2014. Understanding News Geography and Major Determinants of Global News Coverage of Disasters. arXiv:1410.3710 [cs.CY].

8. Kwak H, An J. A First Look at Global News Coverage of Disasters by Using the GDELT Dataset. In: Aiello LM, McFarland D, editors. Social Informatics. SocInfo 2014. Vol. 8851. Cham: Springer; 2014. Lecture Notes in Computer Science.

9. Kwak H, An J. 2016. Two Tales of the World: Comparison of Widely Used World News Datasets GDELT and Event Registry. Proceedings of the Tenth International Conference on Web and Social Media (ICWSM 2016).

10. Mayer - Schonberger V, Cukier K. Big Data: The Essential Guide to Work, Life and Learning in the Age of Insight. Great Britain: Hachet UK Company; 2017.

11. Miles $B$, Morse $S$. The role of news media in natural disaster risk and recovery. Ecol Econ. 2007;63:365-73.

12. Nourbakhsh A, Li Q, Liu X, Shah S. 2017. "Breaking” Disasters: Predicting and Characterizing the Global News Value of Natural and Man-made Disasters. arXiv:1709.02510 [cs.SI].

13. Wu HD. Investigating the determinants of international news flow a meta-analysis. International Communication Gazette. 1998;60(6):493-512.

\section{Figures}

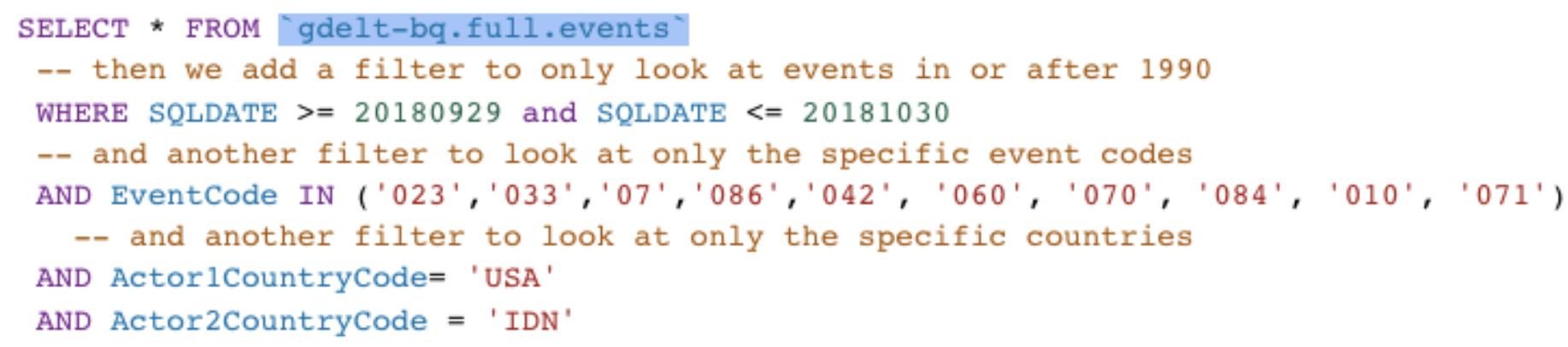

\section{Figure 1}

BigQuery Syntax Example 


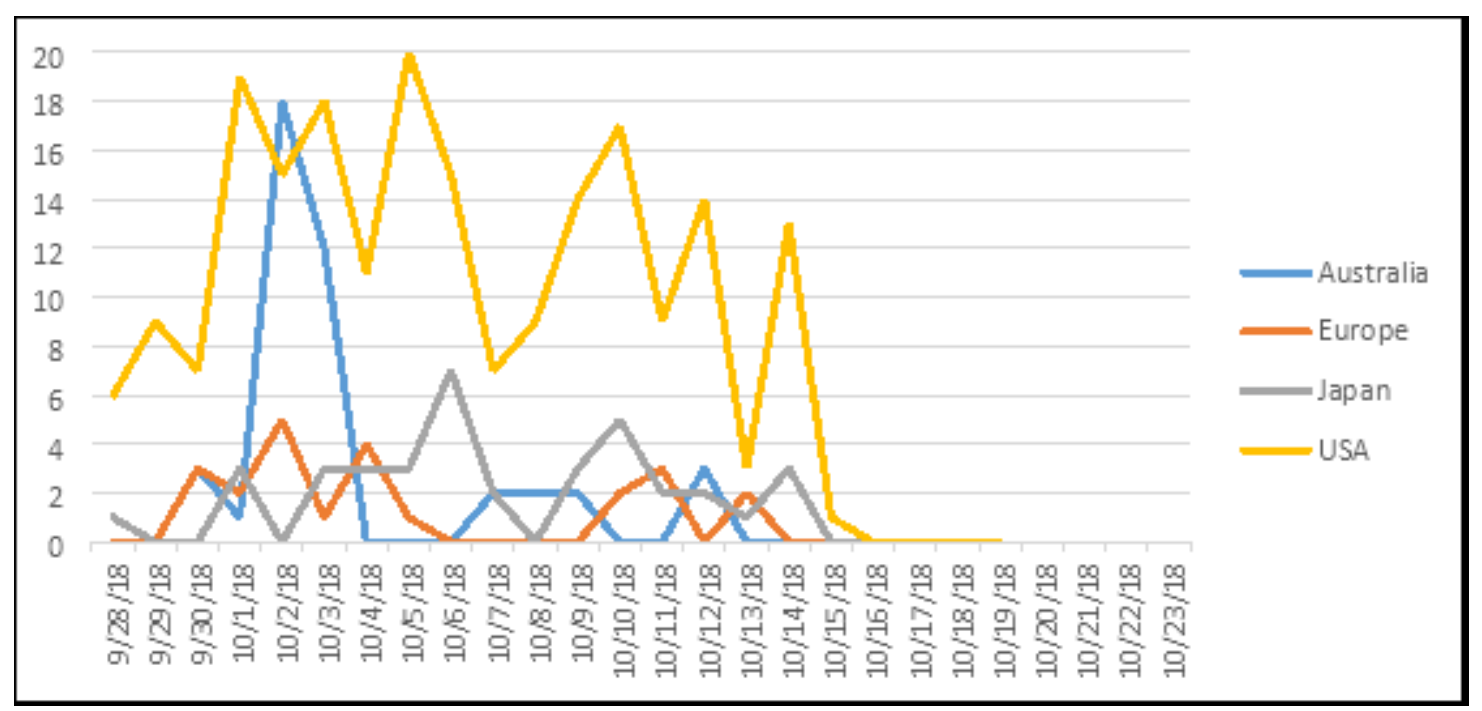

Figure 2

Number of Palu and Donggala Disaster News by Country

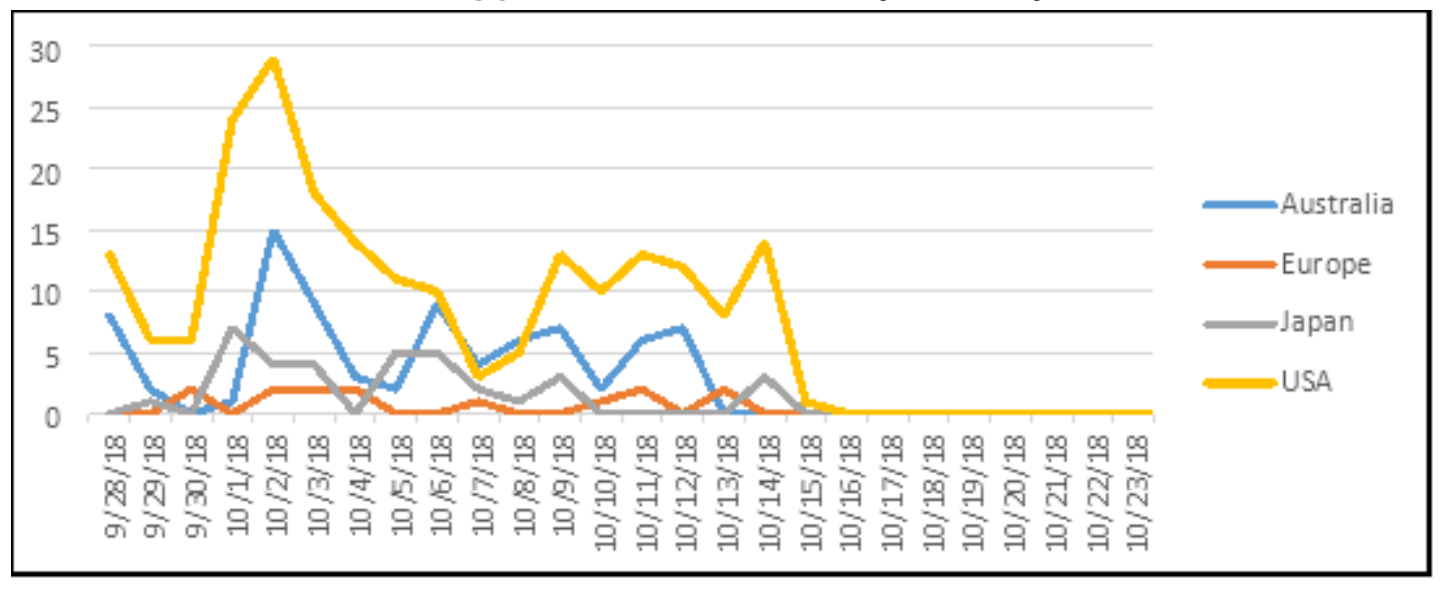

Figure 3

News by Country Number of News Coverage on Selected Countries activities related with Palu and Donggala, reported by Indonesian Media Note: The designations employed and the presentation of the material on this map do not imply the expression of any opinion whatsoever on the part of Research Square concerning the legal status of any country, territory, city or area or of its authorities, or concerning the delimitation of its frontiers or boundaries. This map has been provided by the authors. 


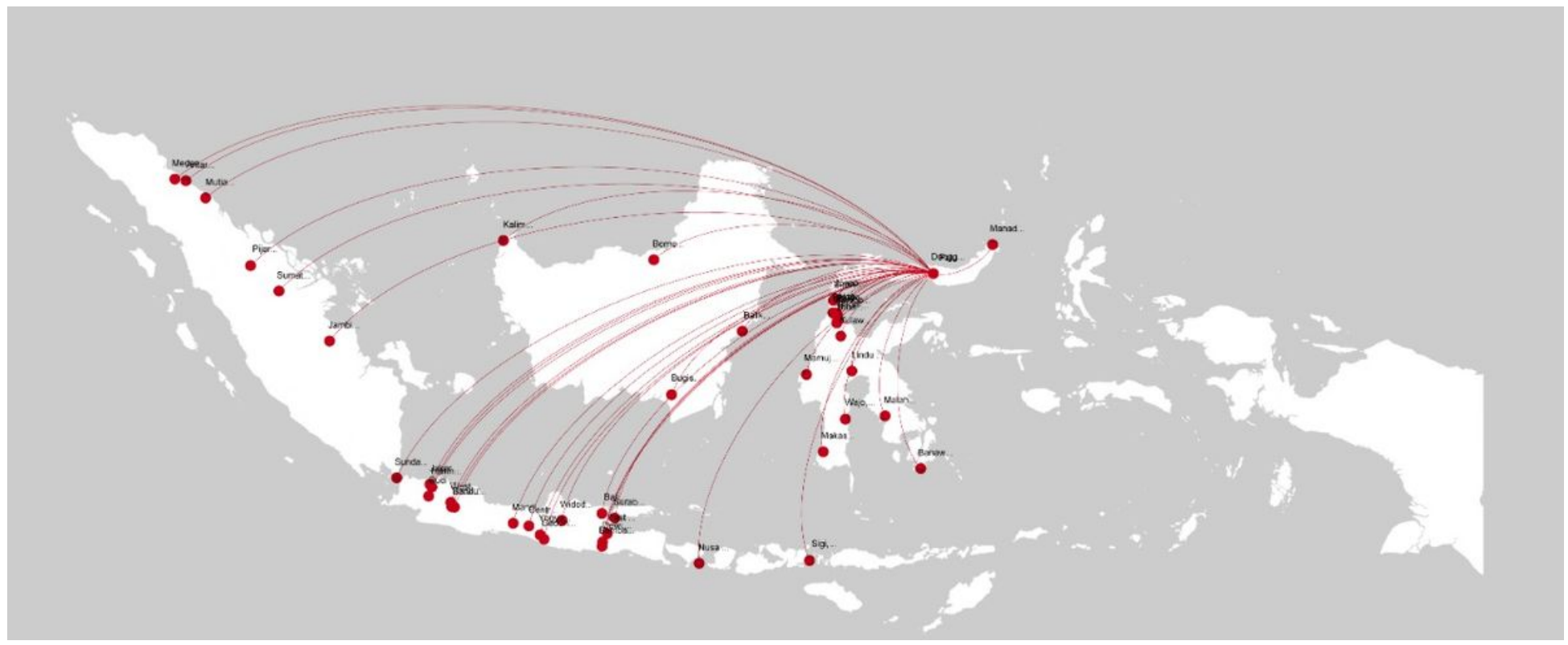

\section{Figure 4}

Domestic News flow on the Palu and Donggala Disaster Note: The designations employed and the presentation of the material on this map do not imply the expression of any opinion whatsoever on the part of Research Square concerning the legal status of any country, territory, city or area or of its authorities, or concerning the delimitation of its frontiers or boundaries. This map has been provided by the authors.

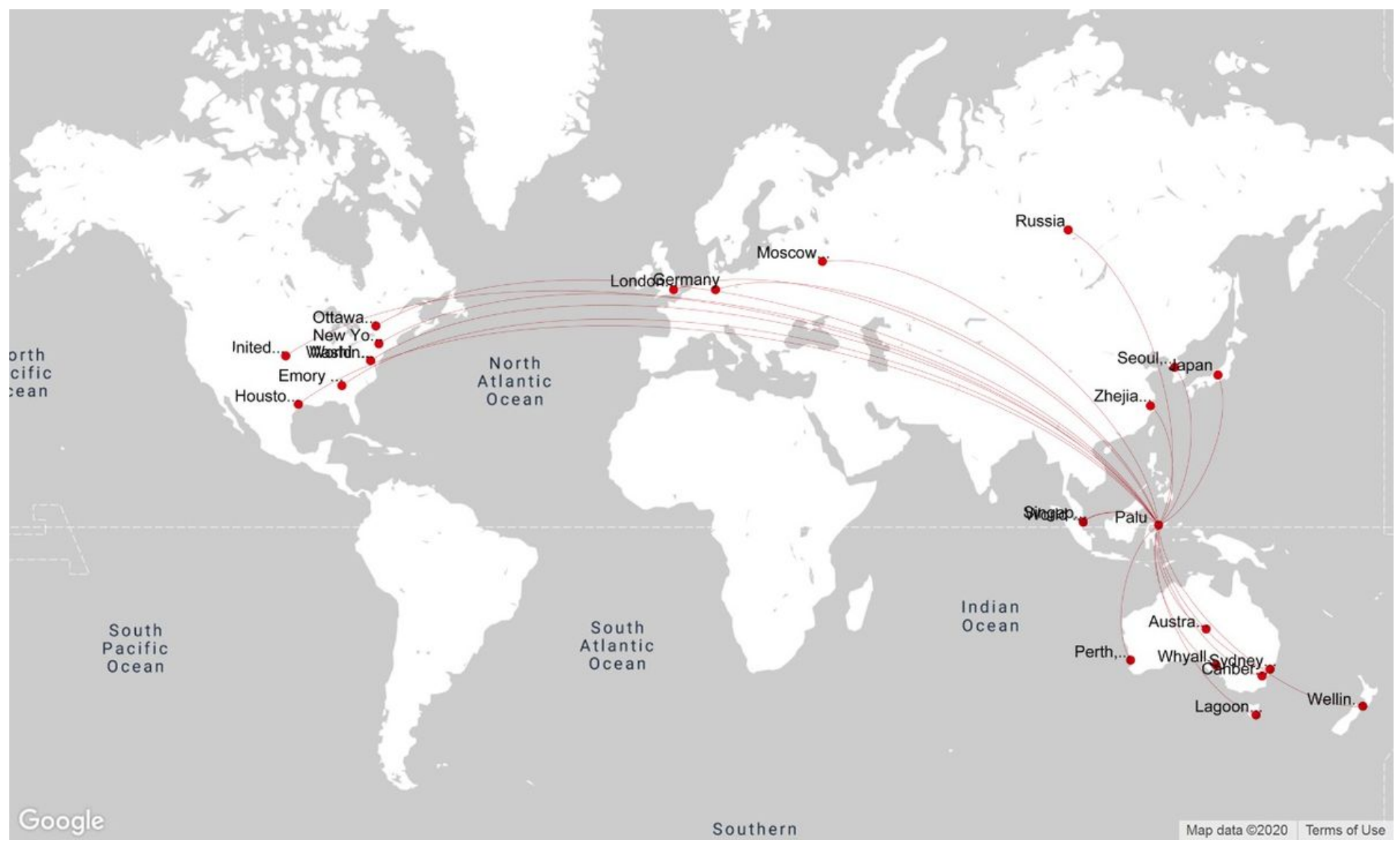




\section{Figure 5}

International News flow on the Palu and Donggala Disaster Note: The designations employed and the presentation of the material on this map do not imply the expression of any opinion whatsoever on the part of Research Square concerning the legal status of any country, territory, city or area or of its authorities, or concerning the delimitation of its frontiers or boundaries. This map has been provided by the authors. 